\title{
SOSTDC1 inhibits bone metastasis in non-small cell lung cancer and may serve as a clinical therapeutic target
}

\author{
GUANGHUI CHEN $^{1 *}$, HAIYI GONG ${ }^{*}$, TING WANG ${ }^{1 *}$, JIAN WANG $^{2}$, ZHITAO HAN $^{1,3}$, GUANGJIAN BAI $^{4}$, \\ SHUAI HAN ${ }^{1}$, XINGHAI YANG ${ }^{1}$, WANG ZHOU ${ }^{1,5}$, TIELONG LIU ${ }^{1}$ and JIANRU XIAO ${ }^{1}$ \\ ${ }^{1}$ Orthopedic Oncology Center, Changzheng Hospital, Second Military Medical University, Shanghai 200003; \\ ${ }^{2}$ Department of Orthopedics, Pudong New District People's Hospital, Shanghai 201200; \\ ${ }^{3}$ School of Medicine and Life Sciences, Nanjing University of Traditional Chinese Medicine, Nanjing, Jiangsu 210023; \\ ${ }^{4}$ Department of Orthopedics, Affiliated Hospital of Taishan Medical University, Taishan Medical University, \\ Tai'an, Shandong 271016; ${ }^{5}$ School of Clinical Medicine, Tsinghua University, Beijing 102218, P.R. China
}

Received January 26, 2018; Accepted September 27, 2018

DOI: $10.3892 / \mathrm{ijmm} .2018 .3926$

\begin{abstract}
Bone metastasis occurs in $\sim 40 \%$ patients with non-small cell lung cancer (NSCLC), resulting in serious morbidity and mortality. Sclerostin domain-containing protein 1 (SOSTDC1) has been demonstrated to be associated with the development and progression of multiple types of cancer. However, the role of SOSTDC1 in NSCLC bone metastasis remains unclear. In the present study, it was identified that SOSTDC1 was downregulated in NSCLC bone metastatic lesions compared with that in primary tumors, and low SOSTDC1 expression predicted poor prognosis for patients with NSCLC. Functionally, SOSTDC1 overexpression suppressed NSCLC cell proliferation, migration, invasion and cancer cell-induced osteoclastogenesis, while SOSTDC1 knockdown produced the opposite effect. In addition, a number of potential downstream target genes of SOSTDC1, which were demonstrated to be associated with tumor progression and bone metastasis, were identified in NSCLC cells by RNA deep sequencing and RT-qPCR assays. The results from the present study may provide useful insight for an improved understanding of the pathogenesis of NSCLC bone metastasis, and suggest that SOSTDC1 may be a potential prognostic biomarker and therapeutic target for NSCLC bone metastasis.
\end{abstract}

Correspondence to: Professor Jianru Xiao or Professor Tielong Liu, Orthopedic Oncology Center, Changzheng Hospital, Second Military Medical University, 415 Fengyang Road, Shanghai 200003, P.R. China

E-mail: jianruxiao83@163.com

E-mail: czyylt1@163.com

*Contributed equally

Key words: sclerostin domain-containing protein 1, non-small cell lung cancer, bone metastasis, osteoclast differentiation, downstream

\section{Introduction}

Lung cancer is one of the most common types of malignant tumor and the leading cause of cancer-associated mortality (1). The 5-year survival of patients with lung cancer is only $16.6 \%(1,2)$. Non-small cell lung cancer (NSCLC) represents $\sim 85 \%$ of all incident lung cancer cases, with adenocarcinoma, squamous cell carcinoma and large cell carcinoma as the typical histopathological types (3). Bone metastasis occurs in $\sim 40 \%$ of NSCLC cases, resulting in serious morbidities and mortality (4). Patients with NSCLC with bone metastasis often experience severe pain, pathologic bone fracture, spinal cord compression and hypercalcemia, which result in a poor quality of life, decreased survival rates and increases in medical expenditure (5). Despite this clinical importance, the pathological mechanism of bone metastasis in lung cancer remains poorly understood.

Sclerostin domain-containing protein 1 (SOSTDC1), also known as WISE, USAG1 or ectodin, was previously studied in the context of tooth development (6), hair follicle formation (7), limb morphogenesis (8) and trigeminal ganglion formation (9). As a regulator of cell differentiation and proliferation, SOSTDC1 was identified to be associated with the development and progression of multiple types of cancer, including breast, gastric, renal and thyroid cancer (10-13). Zhou et al (14) indicated that SOSTDC1 inhibited thyroid cancer metastasis by regulating epithelial-mesenchymal transition (EMT). Previous studies confirmed SOSTDC1 as a suppressor of Wnt and bone morphogenic protein (BMP) signaling pathways $(15,16)$. However, Zhou et al (14) also suggested that SOSTDC1 may regulate phosphoinositide 3-kinase (PI3K)/protein kinase B (Akt) and mitogen-activated protein kinase (MAPK)/extracellular signal-regulated kinase (Erk) pathways in thyroid cancer, indicating that SOSTDC1 may participate in complex carcinogenic mechanisms. Liu et al (17) demonstrated that SOSTDC1 served as a tumor suppressor through inhibiting proliferation in NSCLC cells. However, the roles and mechanism of SOSTDC1 in NSCLC metastasis, in particular bone metastasis, remain unclear. 
The present study detected the expression of SOSTDC1 in primary and bone metastatic lung cancer tissues, and demonstrated that SOSTDC1 expression was reduced in lung cancer bone metastatic compared with primary NSCLC tissues. Furthermore, through the overexpression or inhibition experiments on SOSTDC1, SOSTDC1 was revealed to inhibit NSCLC cell proliferation, migration, invasion, EMT and cancer cell-induced osteoclastogenesis. Finally, RNA deep sequencing was performed to predict the potential downstream targets of SOSTDC1 in NSCLC. These results indicated that SOSTDC1 may serve key roles in NSCLC bone metastasis.

\section{Materials and methods}

Clinical samples. A total of 141 paratumor lung tissues, 145 NSCLC tissues and 49 lung cancer bone metastatic tissues were collected from patients who underwent surgical resection at Changzheng Hospital of the Second Military Medical University (Shanghai, China) between January 2009 and December 2015. Clinical data of the patients including age, sex, tumor size, the 7th American Joint Committee on Cancer stage (18), pathology grade (19) and the expression level of SOSTDC1 are summarized in Table I. None of the patients received neoadjuvant chemotherapy or radiotherapy prior to surgery. The present study was approved by the Ethics Committee of Second Military Medical University and written informed consent was obtained from the surviving patients, or family members of those who had succumbed.

Immunohistochemistry (IHC). Each tissue sample was fixed in $4 \%$ paraformaldehyde at $4^{\circ} \mathrm{C}$ for $24 \mathrm{~h}$, dehydrated through a graded series of ethanol $(75,85,90$ and $95 \%)$ for $2 \mathrm{~h}$, and finally incubated with absolute ethanol for $1 \mathrm{~h}$ at $4^{\circ} \mathrm{C}$. Samples were then paraffin embedded, sliced into 4- $\mu \mathrm{m}$ sections and stained for rabbit anti-human SOSTDC1 antibody (dilution, 1:1,000; cat. no. ab99340; Abcam, Cambridge, MA, USA). The staining was performed using the Histostain-Plus (DAB) kit (Shanghai Mingrui Biotech Co., Ltd., Shanghai, China) following the manufacturer's protocol. Briefly, sections were heated for antigen retrieval, blocked by $1 \%$ bovine serum albumin (BSA; Servicebio Inc., Wuhan, China), and incubated overnight at $4^{\circ} \mathrm{C}$ with the primary antibody. Subsequent to washing with PBS, the slides were incubated with the goat anti-rabbit IgG horseradish peroxidase (HRP)-conjugated secondary antibody (1:200; cat. no. sc-2004; Santa Cruz Biotechnology, Inc., Dallas, TX, USA) at room temperature for $1 \mathrm{~h}$, and stained with DAB solution for 2-8 min at room temperature under an electron optical microscope (magnification, x100). The staining intensity was scored as follows: 0 , negative; 1 , weakly positive; 2 , moderately positive; and 3 , strongly positive. The positivity was scored by percentage according to four categories: $0,<5 \% ; 1,5-25 \% ; 2,>25-50 \%$; $3,>50-75 \%$; and $4,>75 \%$. The staining score was generated by multiplying the staining intensity score with the percentage of positivity, and was defined as either low expression (score $\leq 2$ ) and high expression (score $\geq 3$ ).

Reverse transcription quantitative polymerase chain reaction (RT-qPCR) assay. Total RNA of clinical samples or cultured cells were isolated using TRIzol ${ }^{\circledR}$ (Thermo Fisher Scientific,
Table I. Patient characteristics.

\begin{tabular}{lcc}
\hline & \multicolumn{2}{c}{ Disease phenotypes } \\
\cline { 2 - 3 } & $\begin{array}{c}\text { Primary } \\
\text { PSCLC }\end{array}$ & $\begin{array}{c}\text { NSCLC bone } \\
\text { metastasis }\end{array}$ \\
\hline Age, years & $60.5 \pm 10.0$ & $53.0 \pm 10.1$ \\
Sex, male/female & $104 / 41$ & $25 / 24$ \\
Types, AD/SCC/unknown & $72 / 73 / 0$ & $30 / 7 / 12$ \\
Size, cm & $4.6 \pm 1.9$ & $4.5 \pm 1.7$ \\
Pathology grade, I/II/III & $16 / 96 / 33$ & - \\
T grade, 1/2/3/4 & $26 / 87 / 28 / 4$ & - \\
N grade, 0/1/2/3 & $82 / 36 / 23 / 4$ & - \\
AJCC grade, $1 / 2 / 3$ & $55 / 54 / 36$ & - \\
SOSTDC1, high/low & $75 / 70$ & $14 / 35$ \\
\end{tabular}

NSCLC, non-small cell lung cancer; AD, adenocarcinoma; SCC, squamous cell carcinoma; AJCC, American Joint Committee on Cancer; SOSTDC1, sclerostin domain-containing protein 1; T, tumor; $\mathrm{N}$, node.

Inc., Waltham, MA, USA) and reverse transcribed into cDNA by using Prime Script ${ }^{\mathrm{TM}}$ RT Master Mix (Takara Bio, Inc., Otsu, Japan). RT was performed at $37^{\circ} \mathrm{C}$ for $30 \mathrm{~min}$ followed by incubation for $5 \mathrm{sec}$ at $85^{\circ} \mathrm{C}$ to inactivate the reverse transcriptase using the Prime Script RT Master Mix (Takara Bio, Inc., Otsu, Japan) according to the manufacturer's protocol. For qPCR, all reactions were performed with a hot-start preincubation step of $5 \mathrm{~min}$ at $95^{\circ} \mathrm{C}$, followed by 40 cycles of $25 \mathrm{sec}$ at $95^{\circ} \mathrm{C}, 30 \mathrm{sec}$ at $58^{\circ} \mathrm{C}$ and $20 \mathrm{sec}$ at $72^{\circ} \mathrm{C}$, and a final $5 \mathrm{~min}$ step at $72^{\circ} \mathrm{C}$ using SYBR-Green qPCR Master Mix (Bimake, Houston, TX, USA) on a 7900HT Fast Real-Time PCR system (Thermo Fisher Scientific, Inc.),. Expression levels were calculated using GAPDH as an internal control with the $2^{-\Delta \Delta \mathrm{Cq}}$ method (20). All primers are summarized in Table II.

Construction of SOSTDC1 overexpression and inhibition plasmids. For the SOSTDC1 overexpression plasmid, a vector pcDNA3.1+ plasmid (Shanghai GeneChem Co., Ltd., Shanghai, China) was enzyme digested by KpnI and EcoRV (Beijing TransGen Biotech Co., Ltd., Beijing, China), and the code sequence of SOSTDC1 (5'-ATGCTTCCTCCTGCCATTCAT TTCTATCTCCTTCCCCTTGCATGCATCCTAATGAAA AGCTGTTTGGCTTTTAAAAATGATGCCACAGAAATC CTTTATTCACATGTGGTTAAACCTGTTCCAGCACAC CCCAGCAGCAACAGCACGTTGAATCAAGCCAGAAAT GGAGGCAGGCATTTCAGTAACACTGGACTGGATCGG AACACTCGGGTTCAAGTGGGTTGCCGGGAACTGCGT TCCACCAAATACATCTCTGATGGCCAGTGCACCAGC ATCAGCCCTCTGAAGGAGCTGGTGTGTGCTGGCGAG TGCTTGCCCCTGCCAGTGCTCCCTAACTGGATTGGA GGAGGCTATGGAACAAAGTACTGGAGCAGGAGGAG CTCCCAGGAGTGGCGGTGTGTCAATGACAAAACCCG TACCCAGAGAATCCAGCTGCAGTGCCAAGATGGCAG CACACGCACCTACAAAATCACAGTAGTCACTGCCTGC AAGTGCAAGAGGTACACCCGGCAGCACAACGAGTCC 
Table II. Polymerase chain reaction primers used in the present study.

\begin{tabular}{|c|c|c|c|}
\hline Gene name & Forward & Reverse & Product length, bp \\
\hline Human SOSTDC1 & AACAGCACGTTGAATCAAGCC & GCCATCAGAGATGTATTTGGTGG & 123 \\
\hline Mouse TRAP & GCCCTTACTACCGTTTGC & TCTCGTCCTGAAGATACTGC & 351 \\
\hline Mouse NFATc1 & CTCACCACAGGGCTCACTA & GATGGCTCGCATGTTATTT & 284 \\
\hline Mouse CTSK & AGTAGCCACGCTTCCTAT & CATCCACCTTGCTGTTAT & 182 \\
\hline Human PAK6 & ACCAATAGGCATGGAATGAAGG & GCGGTCGGAAAGAGGAGTTG & 247 \\
\hline Human CCL3 & CCGTCACCTGCTCAGAATC & CTGCTCGTCTCAAAGTAGTCA & 183 \\
\hline Human BTC & CCTGGGTCTAGTGATCCTTCA & CTTTCCGCTTTGATTGTGTGG & 131 \\
\hline Human WNT10A & GGAGACTCGCAACAAGATCCC & CGATGGCGTAGGCAAAAGC & 80 \\
\hline Human CXCL10 & CCAAGGGTACTAAGGAATC & AGGTAGCCACTGAAAGAAT & 165 \\
\hline Human CXCL2 & GAGGCTGAGGAATCCAAGA & CACAGAGGGAAACACTGCA & 253 \\
\hline Human CXCL1 & CCCCAAGAACATCCAAAGT & GGAACAGCCACCAGTGAGC & 202 \\
\hline Human CXCL8 & TGGCAGCCTTCCTGATTT & СТТСТССАСААСССТСТG & 245 \\
\hline Human GAPDH & GGAGTCCACTGGCGTCTTCA & GGGGTGCTAAGCAGTTGGTG & 191 \\
\hline Mouse GAPDH & TGTTTCCTCGTCCCGTAG & CAАTCTCCACTTTGCСАCT & 108 \\
\hline SOSTDC1-CDS & $\begin{array}{l}\text { AACTTAAGCTTGGTACATGCTTC } \\
\text { CTCCTGCCATTCAT }\end{array}$ & $\begin{array}{l}\text { GCCACTGTGCTGGATCTAACTCA } \\
\text { TGCTGTGCTT }\end{array}$ & 652 \\
\hline SOSTDC1-sh1 & $\begin{array}{l}\text { GTGGAAAGGACGCGGCGGGAA } \\
\text { CTGCGTTCCACCAAATATTCAAG } \\
\text { ACGTATTTGGTGGAACGCAGTTC } \\
\text { CTTTTTTCCCGGGACGCGTTA }\end{array}$ & $\begin{array}{l}\text { TAACGCGTCCCGGGAAAAAAGG } \\
\text { AACTGCGTTCCACCAAATACGTC } \\
\text { TTGAATATTTGGTGGAACGCAGT } \\
\text { TCCCGCCGCGTCCTTTCCAC }\end{array}$ & 88 \\
\hline SOSTDC1-sh2 & $\begin{array}{l}\text { GTGGAAAGGACGCGGCGGCATTT } \\
\text { CAGTAACACTGGACTTTCAAGAC } \\
\text { GAGTCCAGTGTTACTGAAATGCT } \\
\text { TTTTTCCCGGGACGCGTTA }\end{array}$ & $\begin{array}{l}\text { TAACGCGTCCCGGGAAAAAAGC } \\
\text { ATTTCAGTAACACTGGACTCGTC } \\
\text { TTGAAAGTCCAGTGTTACTGAAA } \\
\text { TGCCGCCGCGTCCTTTCCAC }\end{array}$ & 88 \\
\hline
\end{tabular}

SOSTDC1, sclerostin domain-containing protein 1; TRAP, tartrate-resistant acid phosphatase; NFATc1, nuclear factor of activated T cells, cytoplasmic 1; CTSK, cathepsin K; PAK6; P21 (RAC1) activated kinase 6; CCL3, C-C motif chemokine ligand 3; BTC, betacellulin; WNT10A, Wnt family member 10A; CXCL1, C-X-C motif chemokine (CXC) ligand 1; CXCL2 CXC ligand 2; CXCL8, CXC ligand 8; CXCL10, CXC ligand 10; CDS, coding sequence; sh, short hairpin.

AGTCACAACTTTGAGAGCATGTCACCTGCCAAGCCA GTCCAGCATCACAGAGAGCGGAAAAGAGCCAGCAAA TCCAGCAAGCACAGCATGAGTTAG-3') was amplified by PCR $\left(5\right.$ min at $94^{\circ} \mathrm{C}$, followed by 35 cycles of $30 \mathrm{sec}$ at $94^{\circ} \mathrm{C}$, $30 \mathrm{sec}$ at $60^{\circ} \mathrm{C}, 40 \mathrm{sec}$ at $72^{\circ} \mathrm{C}$ and a final $5 \mathrm{~min}$ step at $\left.72^{\circ} \mathrm{C}\right)$ and inserted into pcDNA3.1+ using a Quick-Fusion Cloning kit (Bimake) according to the manufacturer's protocol. For the SOSTDC1 short hairpin RNA (shRNA) plasmids, the vector pGenesil-1 plasmid (Shanghai GeneChem Co., Ltd.) was enzyme digested by HindIII and BamH I (Beijing TransGen Biotech Co., Ltd.). The target sequences were synthesized (Genewiz Co., Ltd., Shuzhou, China) and inserted by using Quick-Fusion Cloning kit (Bimake) according to the manufacturer's protocol (40 ng plasmids combined with $40 \mathrm{ng}$ shRNA fragments). The PCR primers and shRNA targets are summarized in Table II.

Cell lines and culture. The NSCLC A549 and PC9 cell lines (Cell Bank of the Type Culture Collection Committee of the Chinese Academy of Science, Shanghai, China) were routinely maintained in DMEM (A549) and RPMI-1640 (PC9) (both from Invitrogen; Thermo Fisher Scientific, Inc.) supplemented with $10 \%$ fetal bovine serum (FBS; Gibco; Thermo Fisher Scientific, Inc.), respectively. The RNA samples of MRC-5, H1299, H522, H226, SK-MES-1 and H460 cells were kindly provided by Institute of Biomedical Sciences and School of Life Sciences, East China Normal University, China. Bone marrow macrophages (BMMs) were isolated from C57/BL6 mice ( $\mathrm{n}=4$; Laboratory Animal Center, Second Military Medical University; male; 6-7 weeks) cultured in $\alpha$-minimum essential medium (Invitrogen; Thermo Fisher Scientific, Inc.) supplemented with $10 \%$ FBS as described previously (21). Mice were housed in a specific pathogen-free laboratory animal center at a temperature of $20-26^{\circ} \mathrm{C}$ in a standard atmosphere, and were kept on a 12/12 h light-dark cycle, and fed using standard rodent chow. Cells in the logarithmic growth phase were transfected using DNA Transfection Reagent (Bimake) once they reached 50-70\% confluence, according to the manufacturer's protocol.

Western blot analysis. Cells were harvested with radioimmunoprecipitation assay lysis buffer at $0^{\circ} \mathrm{C}$ for $30 \mathrm{~min}$ to obtain total proteins. Proteins were quantified using a BCA Protein Assay kit (cat. no.P0012S; Beyotime Institute of Biotechnology, 
Table III. Univariate and multivariate analyses of different prognostic factors for overall survival in 145 patients with non-small cell lung cancer.

\begin{tabular}{|c|c|c|c|c|c|c|}
\hline \multirow[b]{2}{*}{ Prognostic factors } & \multicolumn{3}{|c|}{ Univariate analysis } & \multicolumn{3}{|c|}{ Multivariate analysis } \\
\hline & HR & $95 \% \mathrm{CI}$ & P-value & $\mathrm{HR}$ & $95 \% \mathrm{CI}$ & P-value \\
\hline Age (>60 vs. $\leq 60)$ & 1.519 & $0.845-2.731$ & 0.162 & - & - & - \\
\hline Sex (female vs. male) & 0.690 & $0.357-1.333$ & 0.269 & - & - & - \\
\hline Types (AD vs. SCC) & 1.277 & $0.709-2.299$ & 0.416 & - & - & - \\
\hline Size, cm (>5 vs. $\leq 5)$ & 1.838 & $1.030-3.281$ & $0.040^{\mathrm{a}}$ & 1.778 & $0.918-3.441$ & 0.088 \\
\hline Pathology grade (II vs. I) & 4.181 & $0.990-17.661$ & 0.052 & 2.621 & $0.603-11.394$ & 0.199 \\
\hline Pathology grade (III vs. I) & 4.439 & $0.975-20.202$ & 0.054 & 3.072 & $0.669-14.113$ & 0.149 \\
\hline T grade (3-4 vs. 1-2) & 2.216 & $1.225-4.011$ & $0.009^{\mathrm{a}}$ & 0.525 & $0.134-2.057$ & 0.355 \\
\hline $\mathrm{N}$ grade (1-3 vs. 0$)$ & 1.912 & $1.075-3.402$ & $0.027^{\mathrm{a}}$ & 1.063 & $0.520-2.175$ & 0.866 \\
\hline AJCC grade (2 vs. 1 ) & 0.939 & $0.421-2.097$ & 0.879 & 0.644 & $0.263-1.573$ & 0.334 \\
\hline AJCC grade (3 vs. 1) & 3.619 & $1.802-7.270$ & $<0.001^{\mathrm{a}}$ & 2.445 & $1.112-5.376$ & $0.026^{\mathrm{a}}$ \\
\hline SOSTDC1 (high vs. low) & 0.449 & $0.248-0.812$ & $0.008^{\mathrm{a}}$ & 0.505 & $0.276-0.922$ & $0.026^{\mathrm{a}}$ \\
\hline
\end{tabular}

${ }^{\mathrm{a}} \mathrm{P}<0.05$. HR, hazard ratio; CI, confidence interval; AJCC, American Joint Committee on Cancer; SOSTDC1, sclerostin domain-containing protein 1 ; $\mathrm{T}$, tumor; $\mathrm{N}$, node.

Shanghai, China), then $20 \mu \mathrm{g}$ protein/lane was separated on $10 \%$ SDS-PAGE gels and transferred onto $0.22-\mathrm{mm}$ nitrocellulose membranes (EMD Millipore, Billerica, MA, USA). The nitrocellulose membranes were blocked using 1\% BSA for $20 \mathrm{~min}$ at $37^{\circ} \mathrm{C}$. Subsequent to washing with TBS for $10 \mathrm{~min}$ at room temperature three times, the membranes were incubated overnight at $4^{\circ} \mathrm{C}$ with primary antibodies against SOSTDC1 (1:1,000; cat. no. ab99340; Abcam), cadherin 1 (1:1,000; CDH1; cat. no. AF7718; Affinity Biosciences, Cincinnati, OH, USA), vimentin (1:1,000; VIM; cat. no. AF7013; Affinity Biosciences), zinc finger protein SNAI (1:1,000; SNAI1; cat. no. AF6032; Affinity Biosciences) and $\beta$-actin $(1: 1,000$; cat. no. AF7018; Affinity Biosciences). The membranes were washed with TBS for $5 \mathrm{~min}$ at room temperature three times. Proteins were detected through incubation of the membranes with HRP-conjugated goat anti-rabbit IgG secondary antibody (1:3,000; cat. no. sc-2004; Santa Cruz Biotechnology, Inc.) at $37^{\circ} \mathrm{C}$ for $2 \mathrm{~h}$.

Cell Counting Kit-8 (CCK-8) assay. A549 and PC9 cells were seeded in 96 -well plates at an initial density of $5 \times 10^{3}$ cells/well, cultured at $37^{\circ} \mathrm{C}$ for $0,12,24,48$ and $72 \mathrm{~h}$, and finally assessed using the CCK-8 (Bimake). The results were measured by absorbance at $450 \mathrm{~nm}$ using an ELx800 microplate reader (BioTek Instruments Inc., USA).

Transwell migration and invasion assay. Transwell chambers (8 $\mu \mathrm{m}$ pore size) without Matrigel ${ }^{\circledR}$ (cat. no. 3422; Corning Incorporated, Corning, NY, USA) or with Matrigel ${ }^{\circledR}$ (cat. no. 354480; Corning Incorporated) were used for Transwell migration or invasion assays, respectively. Cells were digested with Trypsin (Gibco; Thermo Fisher Scientific, Inc.) and counted. A total of $1 \times 10^{5}$ cells in $100 \mu \mathrm{l}$ medium without FBS were plated in the upper chamber and $500 \mu \mathrm{l}$ medium supplemented with $10 \%$ FBS was placed in the bottom chambers as a chemoattractant. Non-migratory cells on the upper membrane surface were carefully removed after $24 \mathrm{~h}$ incubation at $37^{\circ} \mathrm{C}$. Cells on the bottom surface were fixed with $4 \%$ paraformaldehyde for $20 \mathrm{~min}$ at room temperature, stained at room temperature with $0.1 \%$ crystal violet $(1: 1,000)$ for $30 \mathrm{~min}$, then counted by capturing images from five random fields under a light microscope at magnification, $\mathrm{x} 400$.

Osteoclast differentiation assay. BMMs with macrophage colony-stimulating factor (M-CSF) stimulation (PeproTech, Inc., Rocky Hill, NJ, USA) as an osteoclast differentiation model. BMMs were cultured at $37^{\circ} \mathrm{C}$ with the conditional media from A549 or PC9 cells for 7 days. Then, cells were fixed by $4 \%$ paraformaldehyde for $20 \mathrm{~min}$ at room temperature and stained using a tartrate-resistant acid phosphatase (TRAP) staining kit (Sigma-Aldrich; Merck KGaA, Darmstadt, Germany) according to the manufacturer's protocol. TRAP-positive multinucleated cells containing $\geq 3$ nuclei were counted as mature osteoclasts. The osteoclast cell numbers were counted by capturing images from 5 random fields under a light microscope at magnification, $\mathrm{x} 400$.

RNA deep sequencing. PC9 cells were harvested following transfection with OE-SOSTDC1 or OE-CTRL plasmids for $48 \mathrm{~h}$ using DNA Transfection reagent (Bimake) according to the manufacturer's protocol (1.6 ug DNA/1 ml culture medium). Total RNA was extracted from the cells using TRIzol reagent according the manufacturer's protocol, and subjected to RNA deep sequencing at Beijing Genomics Institute (Shenzhen, China) on the BGISEQ-500 platform. The sequence results were obtained as the fragment $/ \mathrm{kB}$ of exons/million reads for each transcript. The pathway analyses of the results of RNA deep sequencing, including Gene Ontology (GO) analysis and Kyoto Encyclopedia of Genes and Genomes (KEGG) pathway analysis, were further performed by Beijing Genomics Institute. 
A
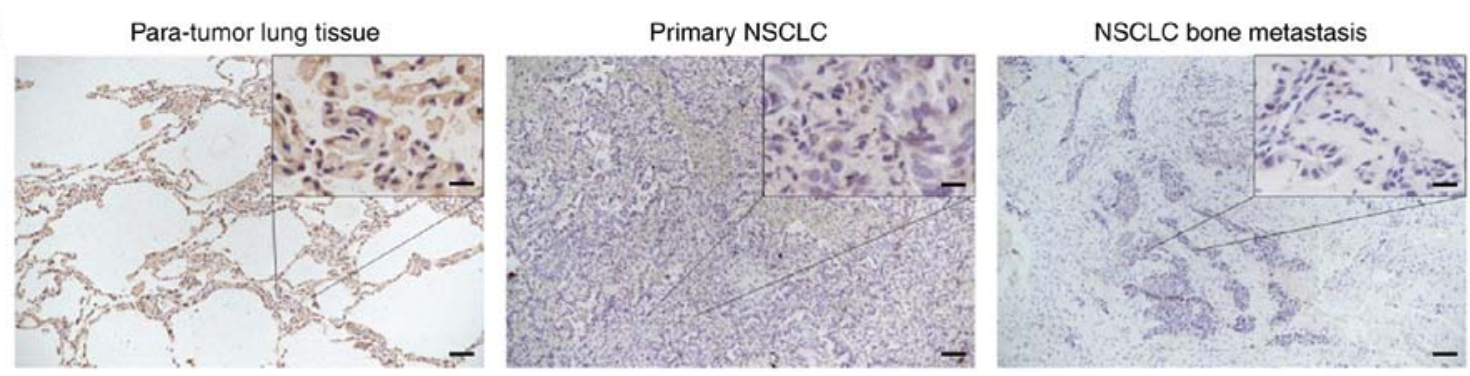

B

\begin{tabular}{|c|c|c|c|}
\hline \multirow{2}{*}{ Samples } & \multicolumn{2}{|c|}{ SOSTDC1 expression } & \multirow{2}{*}{ P-value } \\
\hline & Low & High & \\
\hline Para-tumor lung tissue & $39(27.1 \%)$ & $102(72.3 \%)$ & \multirow{2}{*}{$<0.001$} \\
\hline Primary NSCLC & $70(48.3 \%)$ & $75(51.7 \%)$ & \\
\hline NSCLC bone metastasis & $35(71.4 \%)$ & $14(28.6 \%)$ & 0.005 \\
\hline
\end{tabular}

C

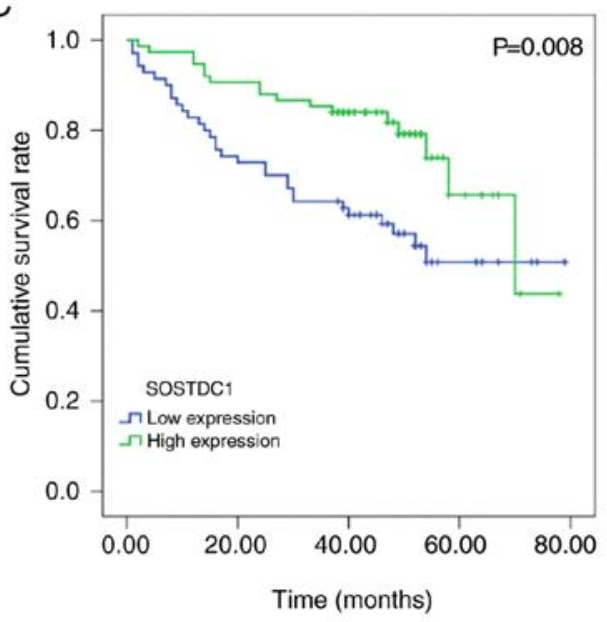

D

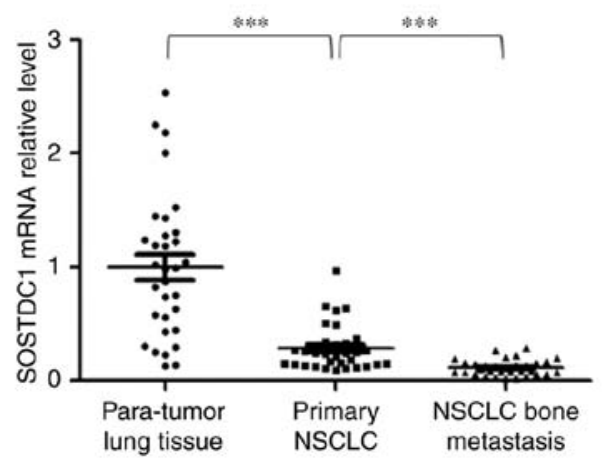

$\mathrm{E}$

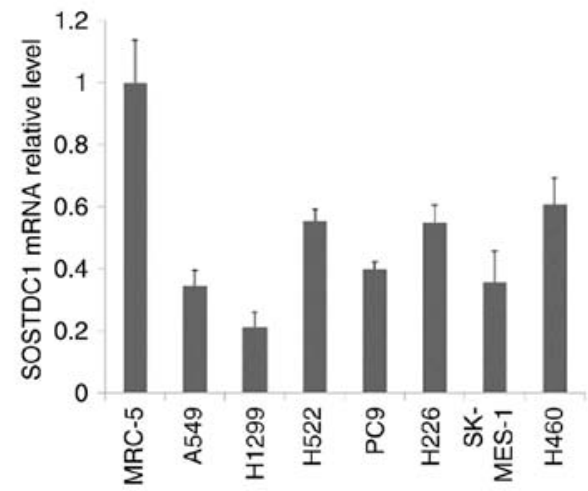

Figure 1. SOSTDC1 is downregulated in NSCLC bone metastasis and associated with the survival outcome of patients with NSCLC. (A) IHC staining of SOSTDC1 in para-tumor lung tissue, primary NSCLC and NSCLC bone metastasis tissues. Scale bars on the full images represent $100 \mu \mathrm{m}$ and those on the magnified images represent $25 \mu \mathrm{m}$. (B) Statistical analysis of IHC staining. (C) Kaplan-Meier analysis of SOSTDC1 expression associated with overall survival in patients with NSCLC. (D) RT-qPCR assay of mRNA level of SOSTDC1 in clinical samples. (E) RT-qPCR assay of mRNA level of SOSTDC1 in various NSCLC cell lines and normal lung cell line. ${ }^{* * *} \mathrm{P}<0.001$. RT-qPCR, reverse transcription quantitative polymerase chain reaction; SOSTDC1, sclerostin domain-containing protein 1; NSCLC, non-small cell lung cancer; IHC, immunohistochemistry.

Statistical analysis. SPSS 19.0 statistical software (IBM Corp., Armonk, NY, USA) was used for statistical analysis. The Kaplan-Meier method was used to establish survival curves, and log-rank test was applied for comparative analysis of differences in patient survival. All data are presented as mean \pm standard error of the mean (SEM). Factors measuring $\mathrm{P} \leq 0.1$ from log-rank tests were subjected to the Cox proportional hazard analysis and calculation of the hazard ratio and 95\% confidence interval. Statistics of the mean value between groups were assessed using one-way analysis of variance followed by the least significant difference method. All experiments were repeated at least three times, and representative experiments are presented. $\mathrm{P}<0.05$ was considered to indicate a statistically significant difference.

\section{Results}

SOSTDC1 is downregulated in NSCLC bone metastatic tissues and associated with the survival outcomes of patients with NSCLC.IHC staining was performed to detect the expression of SOSTDC1 in 141 paratumor lung tissues, 145 primary NSCLC and 49 bone metastatic specimens. The results indicated that SOSTDC1 exhibited clear cytoplasmic expression, was significantly downregulated in primary NSCLC tissues compared with that in non-cancerous lung tissues, and additionally decreased in NSCLC bone metastatic tissues (Fig. 1A and B). In addition, Kaplan-Meier analysis demonstrated that patients with primary NSCLC with high SOSTDC1 expression $(n=75)$ exhibited significantly improved overall survival compared with those with low SOSTDC1 expression (n=70) (Fig. 1C). 
A

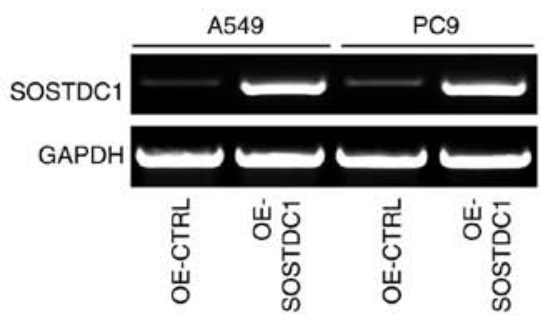

C

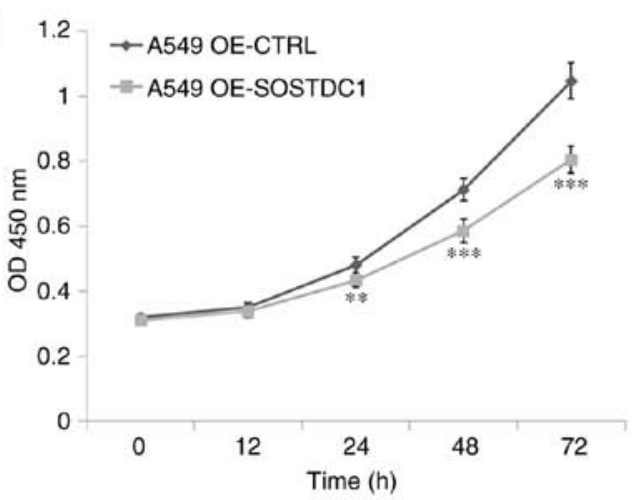

E

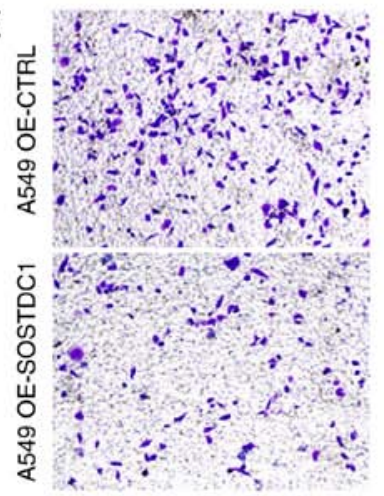

G

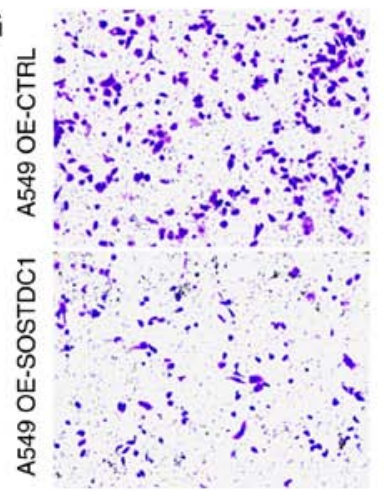

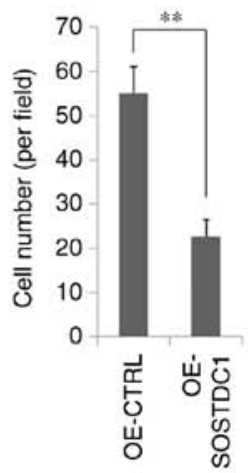

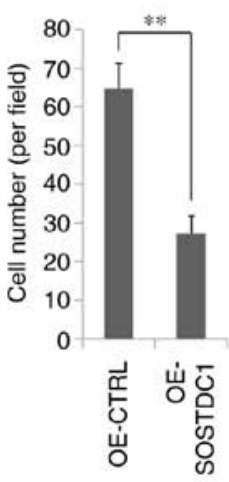

B
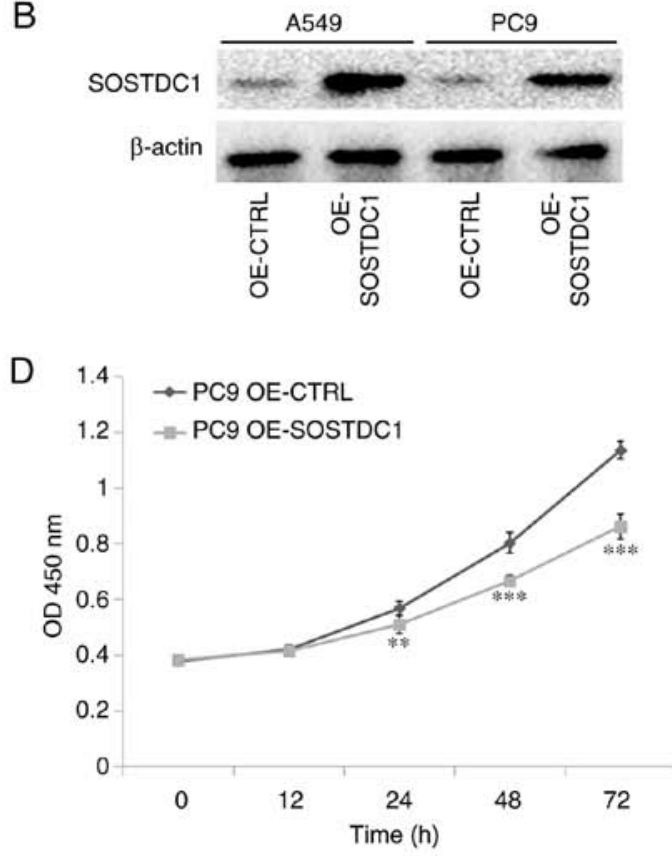

F
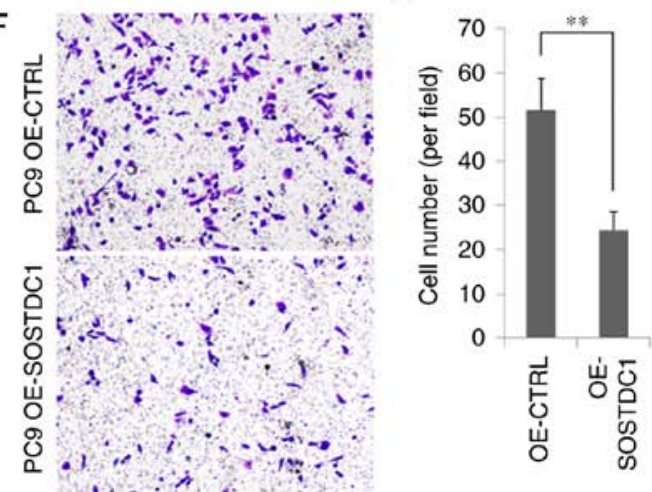

$\mathrm{H}$
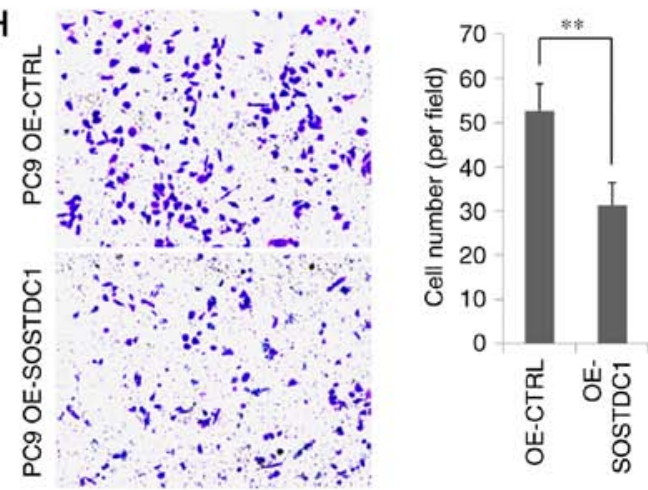

Figure 2. Overexpression of SOSTDC1 inhibits NSCLC cell proliferation, migration and invasion. (A and B) Confirmation of SOSTDC1 overexpression following transfection in A549 and PC9 cells by (A) PCR and (B) western blot analysis. (C) CCK-8 assay of A549 cells following transfection with OE-SOSTDC1 or OE-CTRL plasmids. (D) CCK-8 assay of PC9 cells following transfection. (E) Transwell migration assay of A549 cells following transfection with OE-SOSTDC1 or OE-CTRL plasmids. (F) Transwell migration assay of PC9 cells following transfection. (G) Transwell invasion assay of A549 cells following transfection with OE-SOSTDC1 or OE-CTRL plasmids. (H) Transwell invasion assay of PC9 cells following transfection. ${ }^{* * *} \mathrm{P}<0.01$ and ${ }^{* * *} \mathrm{P}<0.001$. NSCLC, non-small cell lung cancer; SOSTDC1, sclerostin domain-containing protein 1; PCR, polymerase chain reaction; CCK-8, Cell Counting Kit 8; OE, overexpression; CTRL, control.

Multivariate COX analysis of clinical factors additionally identified SOSTDC1 expression as an independent prognostic factor for patients with NSCLC (Table III). Analysis of the association between the clinical factors and SOSTDC1 expression suggested that only $\mathrm{T}$ grade was significantly correlated with the SOSTDC1 expression level (Table IV). The RT-qPCR assay also indicated that the mRNA level of SOSTDC1 was markedly decreased in bone metastatic specimens (Fig. 1D). Then, differences in SOSTDC1 expression between lung cancer cell lines and normal lung cell line (MRC-5) were 
Table IV. Associations between clinical factors and SOSTDC1 expression.

\begin{tabular}{|c|c|c|c|}
\hline \multirow[b]{2}{*}{ Characteristics } & \multicolumn{2}{|c|}{$\begin{array}{l}\text { SOSTDC1 } \\
\text { expression }\end{array}$} & \multirow[b]{2}{*}{ P-value } \\
\hline & Low & High & \\
\hline Age, years & & & 0.096 \\
\hline$>60$ & 42 & 34 & \\
\hline$\leq 60$ & 28 & 41 & \\
\hline Sex & & & 0.581 \\
\hline Male & 52 & 52 & \\
\hline Female & 18 & 23 & \\
\hline Types & & & 1.000 \\
\hline $\mathrm{AD}$ & 35 & 37 & \\
\hline SCC & 35 & 38 & \\
\hline Size, $\mathrm{cm}$ & & & 0.856 \\
\hline$>5$ & 20 & 23 & \\
\hline$\leq 5$ & 50 & 52 & \\
\hline Pathology grade & & & 0.133 \\
\hline $\mathrm{I}$ & 4 & 12 & \\
\hline II & 50 & 46 & \\
\hline III & 16 & 17 & \\
\hline $\mathrm{T}$ grade & & & $0.029^{\mathrm{a}}$ \\
\hline $1-2$ & 49 & 64 & \\
\hline $3-4$ & 21 & 11 & \\
\hline $\mathrm{N}$ grade & & & 0.135 \\
\hline 0 & 35 & 47 & \\
\hline $1-3$ & 35 & 28 & \\
\hline AJCC grade & & & 0.185 \\
\hline 1 & 23 & 32 & \\
\hline 2 & 25 & 29 & \\
\hline 3 & 22 & 14 & \\
\hline Survival & & & $0.008^{\mathrm{a}}$ \\
\hline Yes & 39 & 58 & \\
\hline No & 31 & 17 & \\
\hline
\end{tabular}

${ }^{\mathrm{a}} \mathrm{P}<0.05$. SOSTDC1, sclerostin domain-containing protein 1; AJCC, American Joint Committee on Cancer; AD, adenocarcinoma; SCC, squamous cell carcinoma; $\mathrm{T}$, tumor; $\mathrm{N}$, node.

compared. It was identified that SOSTDC1 was markedly downregulated in NSCLC cancer cells compared with that in MRC-5 (Fig. 1E).

SOSTDC1 overexpression inhibits NSCLC cell proliferation, migration, invasion and EMT. To detect the function of SOSTDC1 in NSCLC cells, aSOSTDC1 overexpression plasmid was constructed and transfected into A549 and PC9 cells. The efficiency of the overexpression plasmid was confirmed by PCR and western blot analysis (Fig. 2A and B). The CCK-8 assay indicated that SOSTDC1 overexpression inhibited A549 and PC9 cell proliferation, and this inhibitory effect became

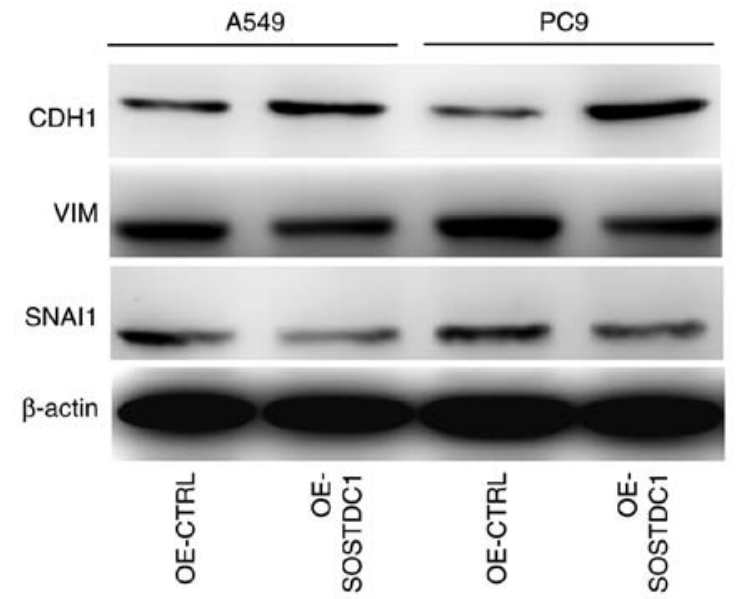

Figure 3. Overexpression of SOSTDC1 inhibits the epithelial-mesenchymal transition process in non-small cell lung cancer cells. The expression levels of epithelial marker CDH1 and the mesenchymal markers VIM and SNAI1 were detected by western blot analysis following the overexpression of SOSTDC1 in A549 and PC9 cells. SOSTDC1, sclerostin domain-containing protein 1; CDH1, cadherin 1; VIM, vimentin; SNAI1, zinc finger protein SNAI1; OE, overexpression; CTRL, control.

more marked over time (Fig. 2C and D). Cell migratory abilities were detected by Transwell assay, and the results demonstrated that the number of A549 and PC9 cells migrating through the chamber membrane in OE-SOSTDC1 plasmid transfection group was decreased significantly compared with that in the control group (Fig. 2E and F). The invasion capability associated with SOSTDC1 expression was examined with Transwell chambers coated with Matrigel. As expected, the number of cells migrating through the membrane was markedly decreased when the expression of SOSTDC1 was upregulated in A549 and PC9 cells (Fig. 3G and H). Knowing that the EMT process is an important factor enhancing cell migration and invasion, the expression of epithelial marker $\mathrm{CDH} 1$ and the mesenchymal markers VIM and SNAI1 following overexpression of SOSTDC1 was detected in A549 and PC9 cells. The results demonstrated that $\mathrm{CDH} 1$ was upregulated while VIM and SNAI1 were downregulated following SOSTDC1 overexpression in NSCLC cells (Fig. 3), indicating that SOSTDC1 may suppress the process of EMT.

SOSTDC1 overexpression inhibits NSCLC cell-induced osteoclast differentiation. To additionally investigate the role of SOSTDC1 in NSCLC bone metastasis, BMMs were selected using M-CSF stimulation for an osteoclast differentiation model. Conditional media from A549 and PC9 cells transfected with OE-CTRL or OE-SOSTDC1 plasmids were used as different stimuli during osteoclastogenesis. The TRAP staining assay indicated that BMMs treated with the conditional media from A549 and PC9 cells transfected with OS-SOSTDC1 plasmid exhibited a decreased level of TRAP positive multinucleated osteoclast formation as compared with the control (Fig. 4A and B). The mRNA levels of nuclear factor of activated T cells, cytoplasmic 1 (NFATc1), TRAP and cathepsin K (CTSK) were detected by RT-qPCR, as NFATc1, TRAP and CTSK are all markers of osteoclasts (22). The results suggested that the mRNA levels of NFATc1, TRAP and CTSK were all significantly decreased in BMMs stimulated 
A

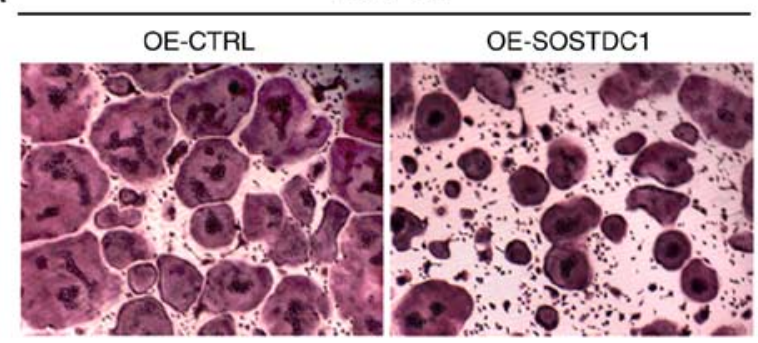

B

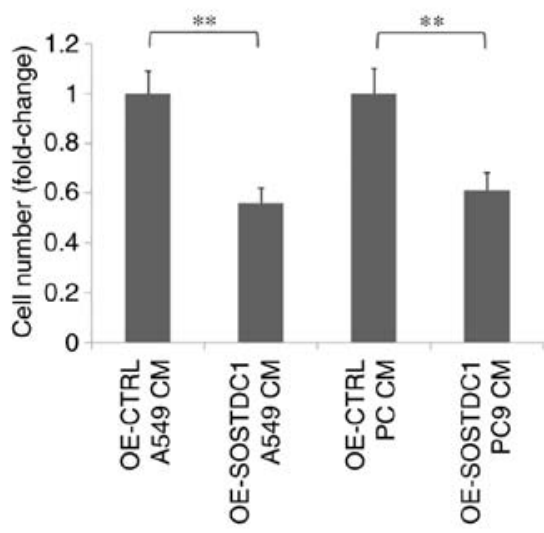

D

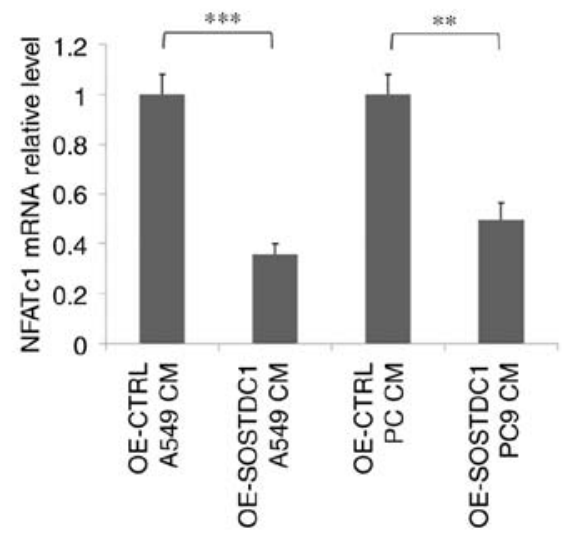

PC9 CM

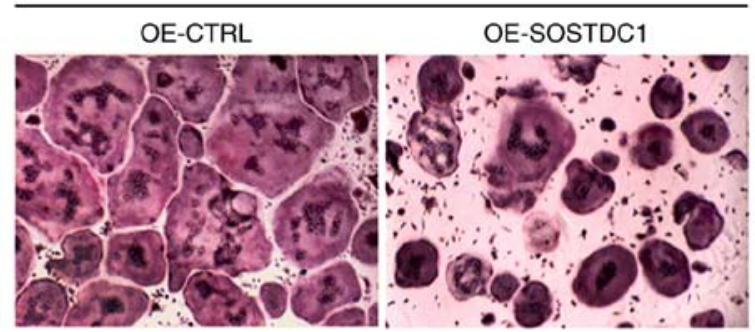

C

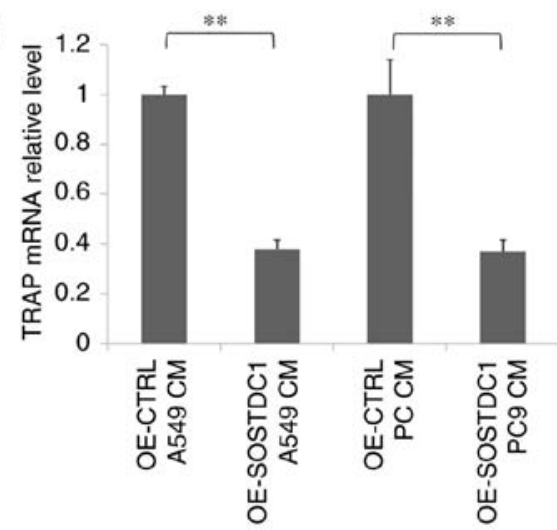

E

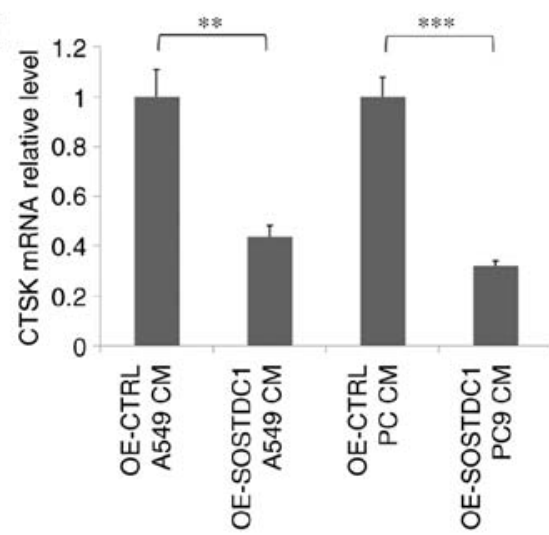

Figure 4. Overexpression of SOSTDC1 inhibits NSCLC cell-induced osteoclast differentiation. (A) Mouse BMMs were seeded and cultured with conditional medium containing macrophage colony-stimulating factor $(10 \mathrm{ng} / \mathrm{ml})$ from A549 or PC9 cells transfected with OE-CTRL or OE-SOSTDC1 plasmids for 7 days. Then, TRAP staining was performed. (B) TRAP-positive osteoclasts were counted. (C) RT-qPCR analysis of mRNA level of TRAP in BMMs. (D) RT-qPCR analysis of NFATc1. (E) RT-qPCR analysis of CTSK. ${ }^{* *} \mathrm{P}<0.01$ and ${ }^{* * *} \mathrm{P}<0.001$. SOSTDC1, sclerostin domain-containing protein 1; OE, overexpression; CTRL, control; TRAP, tartrate-resistant acid phosphatase; RT-qPCR, reverse transcription quantitative polymerase chain reaction; BMMs, bone marrow macrophages; NFATc1, nuclear factor of activated T cells, cytoplasmic 1; CTSK, cathepsin K; CM, conditioned media.

with the conditional media from SOSTDC1 overexpressing A549 and PC9 cells (Fig. 4C-E).

SOSTDC1 inhibition promotes NSCLC cell proliferation, migration, invasion and cancer cell-induced osteoclastogenesis. To additionally confirm the role of SOSTDC1 in NSCLC, two shRNA plasmids for SOSTDC1 were constructed. RT-qPCR and western blot analysis indicated that the sh-SOSTDC1-2 plasmid exhibited an improved inhibitory effect compared with sh-SOSTDC1-1 in A549 and PC9 cells (Fig. 5A and B). Therefore, the sh-SOSTDC1-2 plasmid was used for subsequent experiments. The CCK-8 assay demonstrated that the inhibition of SOSTDC1 promoted the proliferation of A549 and PC9 cells (Fig. 5C and D). Transwell assays revealed that the suppression of SOSTDC1 promoted the migration and invasion of A549 and PC9 cells (Fig. 5E and F). TRAP staining assay of BMMs stimulated with the conditional media from A549 and PC9 cells demonstrated that the inhibition of SOSTDC1 in NSCLC cells significantly decreased the osteoclast formation induced by the cancer cells (Fig. 5G). Concurrently, RT-qPCR assays of TRAP and NFATc1 confirmed the facilitation of SOSTDC1 inhibition in osteoclastogenesis induced by A549 and PC9 cells (Fig. 5H and I). All these data suggest that SOSTDC1 functioned as a tumor suppressor in NSCLC by regulating cell proliferation, migration, invasion and NSCLC-induced osteoclastogenesis.

Analysis of the potential downstream targets of SOSTDC1 in NSCLC. To investigate the mechanism of SOSTDC1 in NSCLC progression, RNA deep sequencing was performed to screen genes responsive to SOSTDC1 overexpression in PC9 cells (Fig. 6A). Pathway analysis indicated that the changed genes were closely associated with cell growth and death, cell 
A

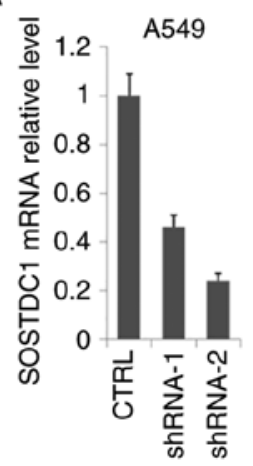

D

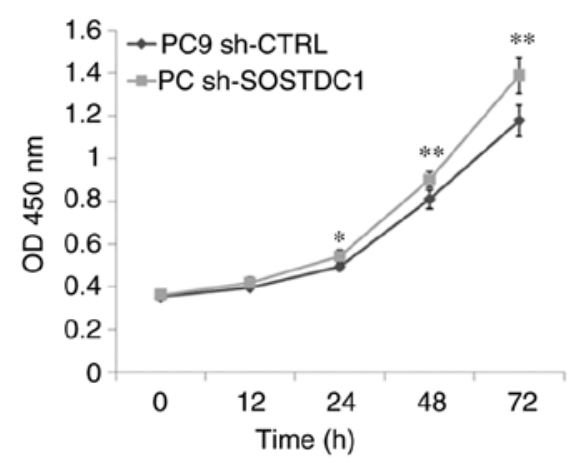

G
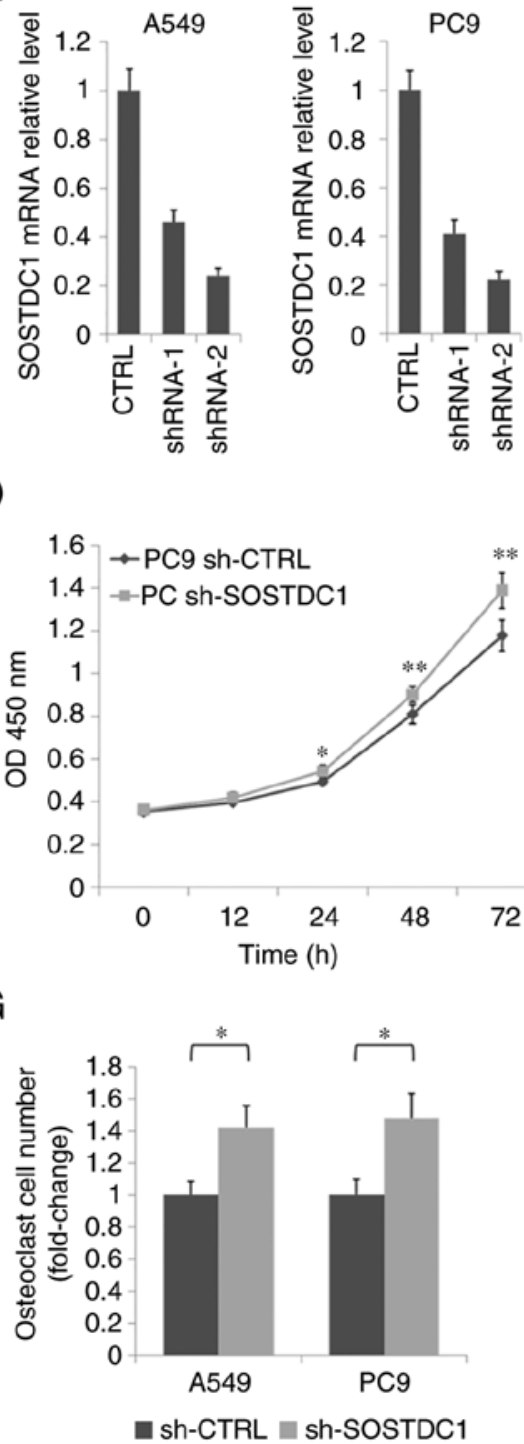

B

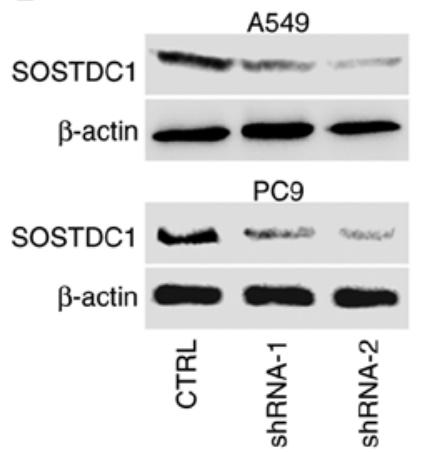

E

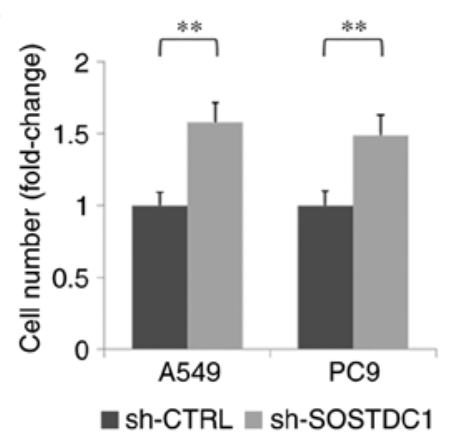

$\mathrm{H}$

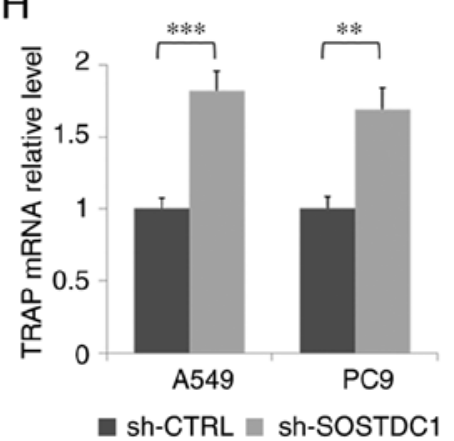

C

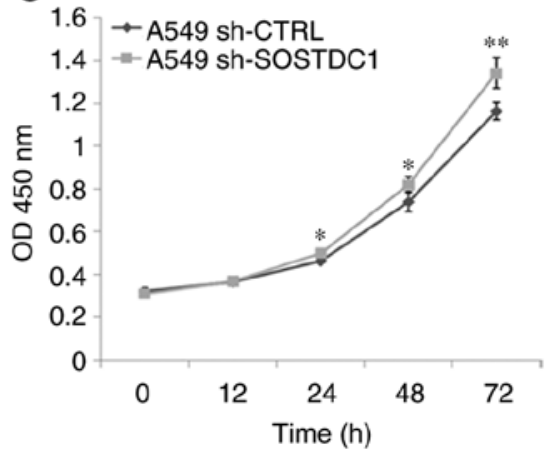

$\mathrm{F}$

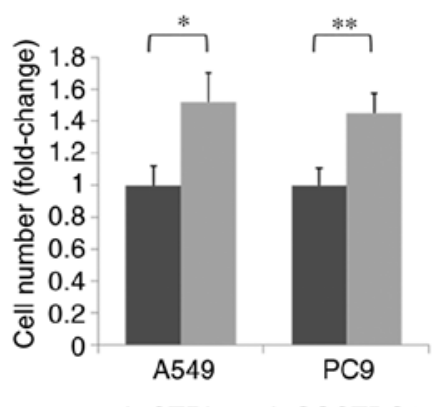

m sh-CTRL $=$ sh-SOSTDC1

I

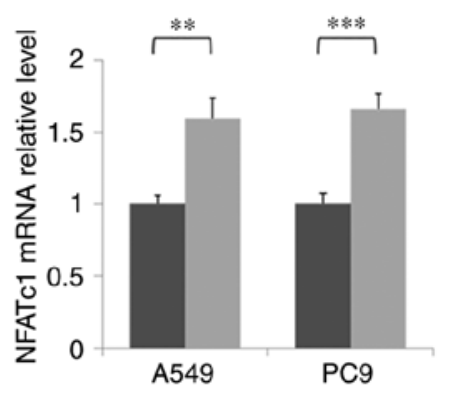

m sh-CTRL $=$ sh-SOSTDC1

Figure 5. Inhibition of SOSTDC1 promotes NSCLC cell proliferation, migration, invasion and cancer cell-induced osteoclastogenesis. (A and B) Confirmation of SOSTDC1 suppression following transfection with shRNA plasmids in A549 and PC9 cells by (A) RT-qPCR and (B) western blot analysis. (C) CCK-8 assay of A549 cells following transfection with SOSTDC1 shRNA plasmids. (D) CCK-8 assay of PC9 cells following transfection with SOSTDC1 shRNA plasmids. (E) Transwell migration assay of A549 and PC9 cells following transfection with sh-CTRL or sh-SOSTDC1 plasmids. (F) Transwell invasion assay of A549 and PC9 cells following transfection with sh-CTRL or sh-SOSTDC1 plasmids. (G) The counting of TRAP-positive osteoclasts in BMMs cultured with conditional medium from A549 or PC9 cells transfected with sh-CTRL or sh-SOSTDC1 plasmids. (H) RT-qPCR analysis of mRNA level of TRAP in BMMs. (I) RT-qPCR analysis of NFATc1. ${ }^{*} \mathrm{P}<0.05,{ }^{* *} \mathrm{P}<0.01$ and ${ }^{* * *} \mathrm{P}<0.001$. SOSTDC1, sclerostin domain-containing protein 1; shRNA, short hairpin RNA; CTRL, control; RT-qPCR, reverse transcription quantitative polymerase chain reaction; TRAP, tartrate-resistant acid phosphatase; BMMs, bone marrow macrophages.

motility, and cancer (Fig. 7). A selection of the altered genes [statistical significance $(\mathrm{P}<0.05)$ with the changed rate $>40 \%$ ] associated with cancer progression are exhibited in Fig. 6B, and RT-qPCR assay was used to validate the decrease in P21 (RAC1) activated kinase 6 (PAK6), C-C motif chemokine ligand 3 (CCL3), B-cell translocation gene (BTG), Wnt family member 10A (WNT10A), C-X-C motif chemokine (CXC) ligand 1 (CXCL1), CXC ligand 2 (CXCL2), CXC ligand 8 (CXCL8) and CXC ligand 10 (CXCL10) mRNA expression following SOSTDC1 overexpression in A549 and PC9 cells (Fig. 6C-J). These results suggest that the mechanisms of SOSTDC 1 in NSCLC progression and bone metastasis require additional investigation.

\section{Discussion}

The present study firstly demonstrated the downregulation of SOSTDC1 in NSCLC bone metastasis compared with primary tumors, and additionally identified that low SOSTDC1 expression in NSCLC predicted poor prognosis of the patients. Functionally, SOSTDC1 overexpression suppressed NSCLC cell proliferation, migration, invasion, EMT and cancer cell-induced osteoclastogenesis, while SOSTDC1 knockdown produced the opposite effect. In addition, RNA deep sequencing and RT-qPCR assays indicated that SOSTDC1 was associated with NSCLC progression and bone metastasis through regulating PAK6, CCL3, BTG, WNT10A, CXCL1, 
A

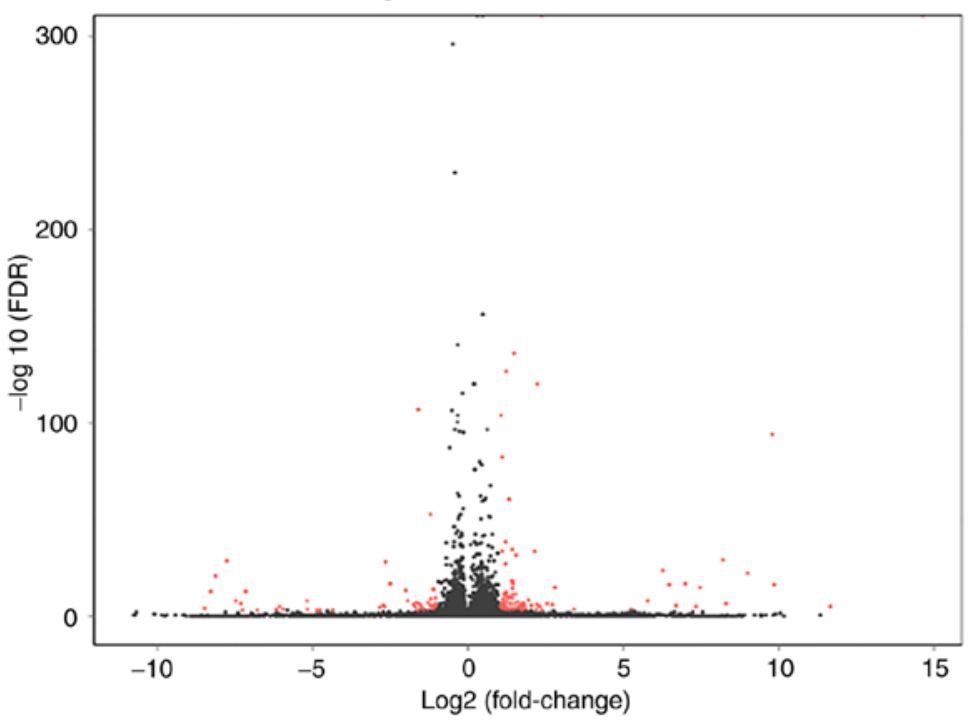

C

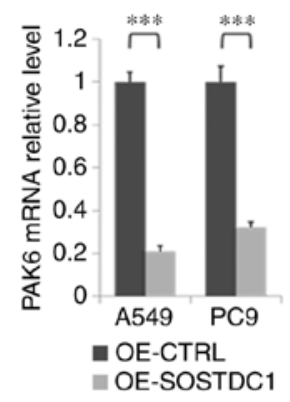

G

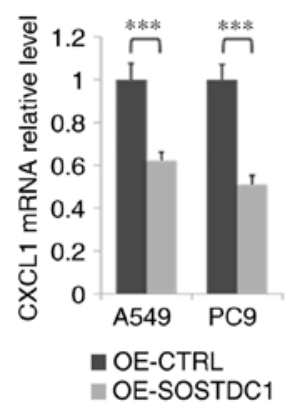

D

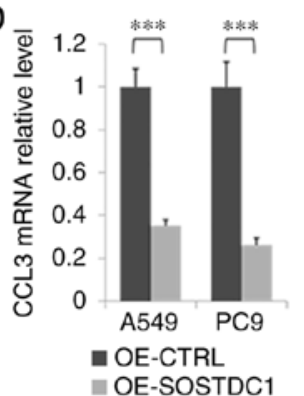

$\mathrm{H}$

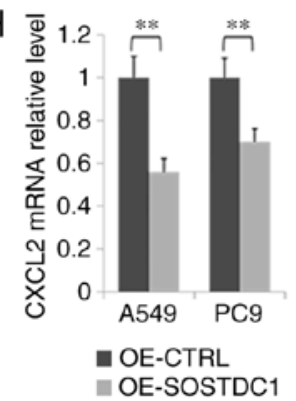

B

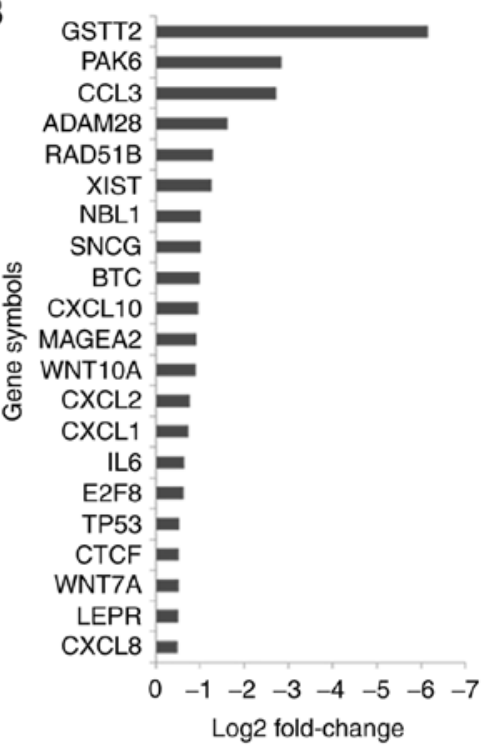

E
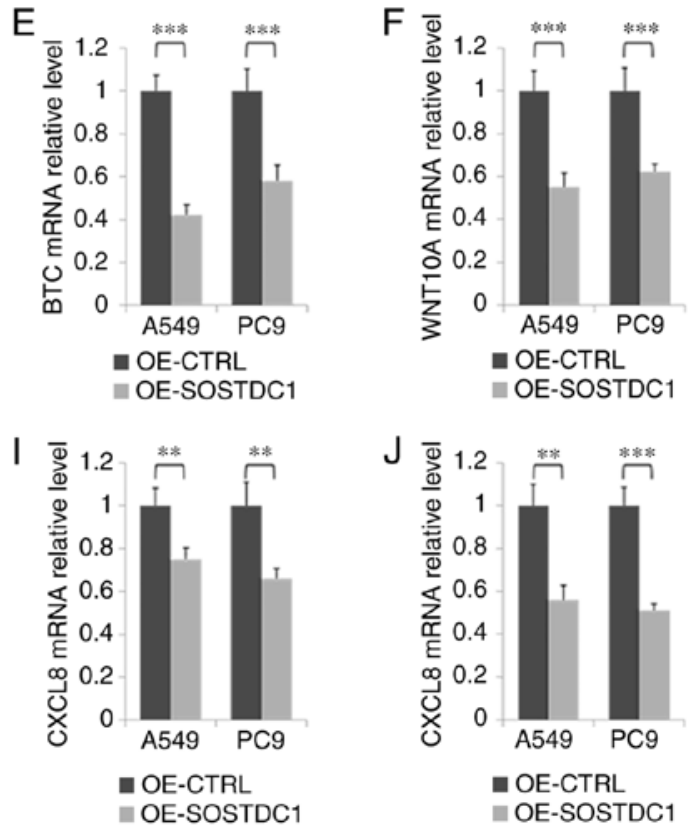

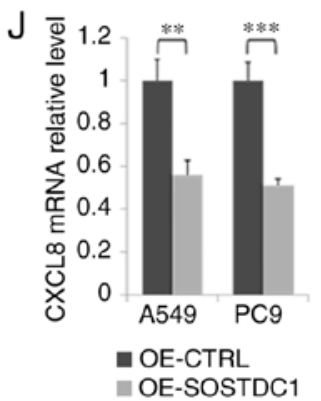

Figure 6. Analysis of potential relevant downstream genes of SOSTDC1 in NSCLC cells. (A) RNA deep sequencing of PC9 cells was performed following transfection with OE-CTRL or OE-SOSTDC1 plasmids. (B) The fold-change of a selection of the genes associated with tumor progression in RNA sequencing. (C-J) RT-qPCR assay was performed to detect changes in mRNA expression of several genes involved in cancer following transfection with OE-CTRL or OE-SOSTDC1 plasmids in A549 and PC9 cells, including (C) PAK6, (D) CCL3, (E) BTC, (F) WNT10A, (G) CXCL1, (H) CXCL2, (I) CXCL8 and (J) CXCL10 ${ }^{* *} \mathrm{P}<0.01$ and ${ }^{* * *} \mathrm{P}<0.001$. OE, overexpression; CTRL, control; SOSTDC1, sclerostin domain-containing protein 1; shRNA, CTRL, control; PAK6; P21 (RAC1) activated kinase 6; CCL3, C-C motif chemokine ligand 3; BTC, betacellulin; WNT10A, Wnt family member 10A; CXCL1, C-X-C motif chemokine (CXC) ligand 1; CXCL2 CXC ligand 2; CXCL8, CXC ligand 8; CXCL10, CXC ligand 10.

CXCL2, CXCL8 and CXCL10. All these results suggest that SOSTDC1 served an inhibitory role in NSCLC progression and bone metastasis.

The formation of NSCLC bone metastasis requires osteolysis and cancer growth induced by the interaction of cancer cells and osteoclasts or its precursors. Previous studies have suggested that SOSTDC1 was downregulated in various types of cancer, while the decreased expression of SOSTDC1 accelerated cell proliferation and predicted poor prognosis in gastric, thyroid and breast cancer (10-12). Zhou et al (14) additionally demonstrated that SOSTDC1 promoted thyroid cancer metastasis by activating EMT. In lung cancer, SOSTDC1 was also confirmed as a tumor suppressor through the regulation of cell proliferation (17). However, whether SOSTDC1 is involved in NSCLC metastasis remains unclear. SOSTDC1 was first examined in 2003 as the antagonist of BMPs (BMP 2, 4, 6 and 7) (23), and later was confirmed to serve key roles in bone remodeling by activating osteoblasts and osteoclasts $(24,25)$. Consistent with the role of BMPs in bone, SOSTDC1 deficiency accelerated fracture healing by promoting the expansion of periosteal mesenchymal stem cells (26). However, to the best of our knowledge, the role of SOSTDC1 in bone metastasis has not yet been described. Due to the potential effects of SOSTDC1 in the bone microenvironment and cancer progression, we hypothesized that SOSTDC1 was involved in the occurrence of bone metastasis. 


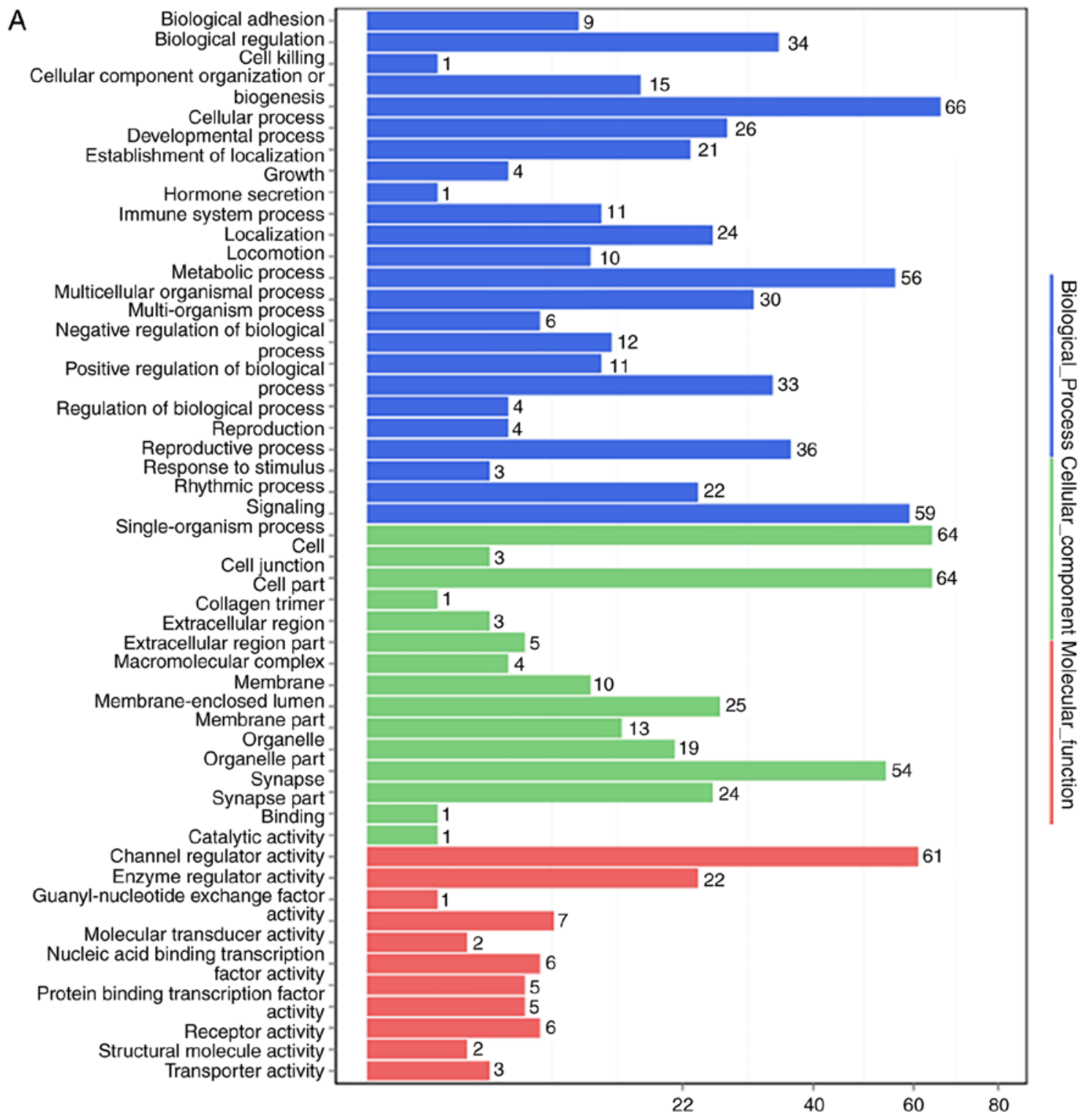

Figure 7. Pathway analysis of the results of RNA deep sequencing in PC9 cells transfected with OE-CTRL or OE-SOSTDC1 plasmids. (A) Gene Ontology analysis.

The result of the present study indicated that SOSTDC1 was downregulated in NSCLC bone metastatic lesions compared with that in primary lesions, and may suppress bone metastasis through inhibiting cell proliferation, migration, invasion, EMT and cancer cell-induced osteoclast differentiation. Knowing that EMT and bone resorption are two key processes during bone metastasis in NSCLC, SOSTDC1 may prove to a potential prognostic biomarker for NSCLC bone metastasis.

Previous studies identified SOSTDC1 as a suppressor of BMP and Wnt signaling pathways: Recently, Togo et al (27) demonstrated that SOSTDC1 antagonized RUNX2 during tooth development. Gopal et al (12) revealed that SOSTDC1 was involved in $\mathrm{CpG}$ methylation in gastric cancer. Zhou et al (14) suggested that SOSTDC1 promoted thyroid cancer progression through the regulation of the PI3K/Akt and MAPK/Erk pathways. Concurrently, SOSTDC1 was demonstrated to be repressed by estrogen (28) and E4BP4 (11), and activated by FGF signaling (29). These data indicate that
SOSTDC1 may participate in complex signaling pathways. Nevertheless, the exact molecular mechanism of SOSTDC1 in NSCLC require elucidation. Therefore, RNA deep sequencing was performed in the present study to explore the potential downstream targets of SOSTDC1 in NSCLC. Notably, it was identified that besides certain components of the Wnt family, several members of the CXCL family (CXCL1/2/8/10) were downregulated following SOSTDC1 overexpression. These CXCLs were considered the downstream targets of the Erk pathway (30) and certain other pathways, including tumor necrosis factor and nuclear factor kappa-light-chain enhancer of activated B cells signaling (31), and identified as the catalyst of osteoclastogenesis and osteolysis $(18,32,33)$. These results may assist in understanding the mechanism of SOSTDC1 in NSCLC bone metastasis. Altogether, the present study demonstrated that SOSTDC1 served a potential role in inhibiting NSCLC bone metastasis, which may provide useful insights for future studies on the treatment of NSCLC bone metastasis. 
B

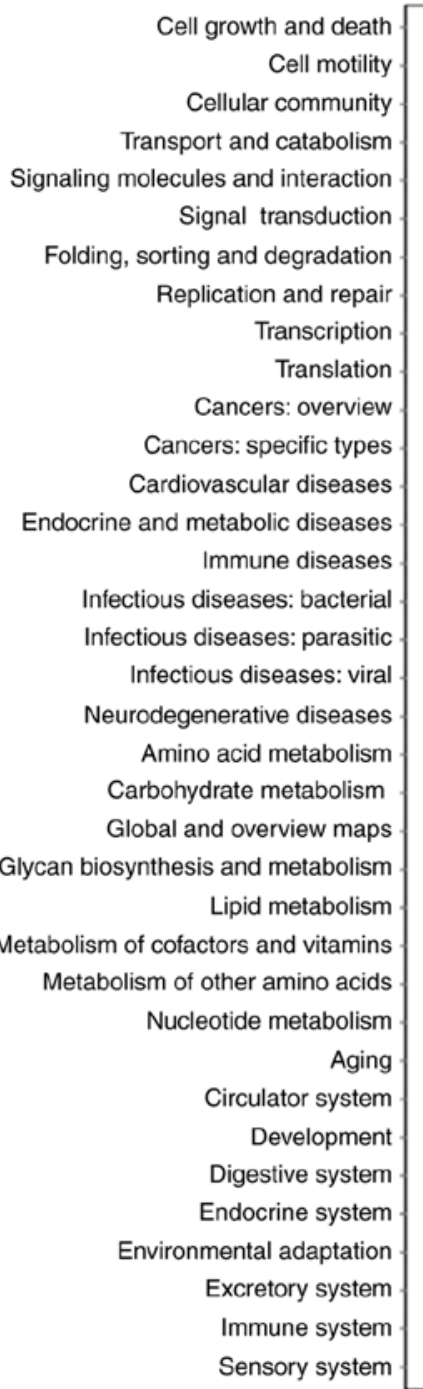

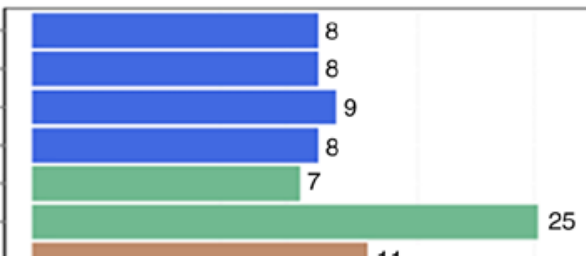

11

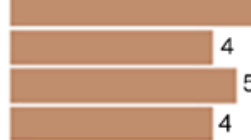

4
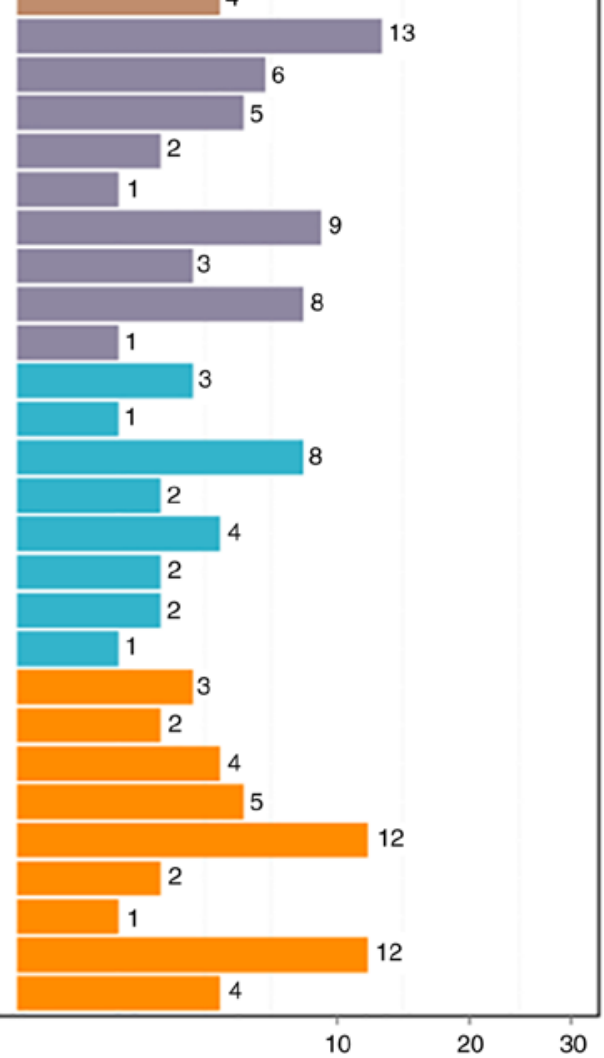

Cellular processes

Environmental information processing

Genetic information processing

Human diseases

Metabolism

Organismal systems

Figure 7. Continued. (B) Kyoto Encyclopedia of Genes and Genomes pathway analysis. OE, overexpression; CTRL, control; SOSTDC1, sclerostin domain-containing protein 1.

Limitations of the present study included the absence of an in vivo experiment of SOSTDC1 in NSCLC bone metastasis, and the incomplete clinical data of the samples, in particular the absence of treatment choice, which may have affected the prognosis of the patients. Additional studies are required to confirm the clinical significance and the molecular mechanism of SOSTDC1 in NSCLC and bone metastasis.

In conclusion, the present study demonstrated that SOSTDC1 was downregulated in NSCLC bone metastasis compared with that in primary tumors, and functioned as a potential tumor suppressor by regulating cell proliferation, migration, invasion, EMT and cancer cell-induced osteoclast differentiation. In addition, a number of potential downstream target genes of SOSTDC1 were identified that may be associated with bone metastasis in NSCLC cells. These data may assist in developing novel diagnostic and treatment strategies for NSCLC bone metastasis.

\section{Acknowledgements}

Not applicable.

\section{Funding}

The present study was supported by the National Natural Science Foundation of China (grant nos. 81501927, 51573207 and 81572641).

\section{Availability of data and materials}

The datasets used and/or analyzed during the current study are available from the corresponding author on reasonable request.

\section{Authors' contributions}

GC, TW and WZ conceived and designed the study; JW, XY and GB analyzed and interpreted the patient data; $\mathrm{HG}, \mathrm{ZH}, \mathrm{SH}$, and GC performed the experiments; GC and TW wrote the manuscript; JX and TL performed the statistical analysis and data presentation; JX, TL and WZ reviewed the manuscript and agreed to be accountable for all aspects of the work; All authors read and approved the manuscript. 


\section{Ethics approval and consent to participate}

The present study was approved by the Ethics Committee of our center and written informed consent was obtained from the surviving patients, or family members of those who had succumbed.

\section{Patient consent for publication}

Not applicable.

\section{Competing interests}

The authors declare that they have no competing interests.

\section{References}

1. Siegel RL, Miller KD and Jemal A: Cancer statistics, 2018. CA Cancer J Clin 68: 7-30, 2018

2. Howlader N, Noone AM, Yu M and Cronin KA: Use of imputed population-based cancer registry data as a method of accounting for missing information: Application to estrogen receptor status for breast cancer. Am J Epidemiol 176: 347-356, 2012.

3. Hoffman PC, Mauer AM and Vokes EE: Lung cancer. Lancet 355: 479-485, 2000.

4. DeSantis CE, Lin CC, Mariotto AB, Siegel RL, Stein KD, Kramer JL, Alteri R, Robbins AS and Jemal A: Cancer treatment and survivorship statistics, 2014. CA Cancer J Clin 64: 252-271, 2014.

5. Vicent S, Luis-Ravelo D, Antón I, García-Tuñón I, Borrás-Cuesta F, Dotor J, De Las Rivas J and Lecanda F: A novel lung cancer signature mediates metastatic bone colonization by a dual mechanism. Cancer Res 68: 2275-2285, 2008.

6. Ahn Y, Sims C, Murray MJ, Kuhlmann PK, Fuentes-Antrás J, Weatherbee SD and Krumlauf R: Multiple modes of Lrp4 function in modulation of $\mathrm{Wnt} / \beta$-catenin signaling during tooth development. Development 144: 2824-2836, 2017.

7. Närhi K, Tummers M, Ahtiainen L, Itoh N, Thesleff I and Mikkola ML: Sostdcl defines the size and number of skin appendage placodes. Dev Biol 364: 149-161, 2012.

8. Collette NM, Yee CS, Murugesh D, Sebastian A, Taher L, Gale NW, Economides AN, Harland RM and Loots GG: Sost and its paralog Sostdc1 coordinate digit number in a Gli3-dependent manner. Dev Biol 383: 90-105, 2013.

9. Shigetani Y, Howard S, Guidato S, Furushima K, Abe T and Itasaki $\mathrm{N}$ : Wise promotes coalescence of cells of neural crest and placode origins in the trigeminal region during head development. Dev Biol 319: 346-358, 2008.

10. Liang W, Guan H, He X, Ke W, Xu L, Liu L, Xiao H and Li Y: Down-regulation of SOSTDC1 promotes thyroid cancer cell proliferation via regulating cyclin A2 and cyclin E2. Oncotarget 6: 31780-31791, 2015.

11. Rawat A, Gopisetty $\mathrm{G}$ and Thangarajan R: E4BP4 is a repressor of epigenetically regulated SOSTDC1 expression in breast cancer cells. Cell Oncol 37: 409-419, 2014.

12. Gopal G, Raja UM, Shirley S, Rajalekshmi KR and Rajkumar T: SOSTDC1 down-regulation of expression involves $\mathrm{CpG}$ methylation and is a potential prognostic marker in gastric cancer. Cancer Genet 206: 174-182, 2013.

13. Blish KR, Wang W, Willingham MC, Du W, Birse CE, Krishnan SR, Brown JC, Hawkins GA, Garvin AJ, D'Agostino RB Jr, et al: A human bone morphogenetic protein antagonist is down-regulated in renal cancer. Mol Biol Cell 19: 457-464, 2008.

14. Zhou Q, Chen J, Feng J, Xu Y, Zheng W and Wang J: SOSTDC1 inhibits follicular thyroid cancer cell proliferation, migration, and EMT via suppressing PI3K/Akt and MAPK/Erk signaling pathways. Mol Cell Biochem 435: 87-95, 2017.

15. Henley KD, Gooding KA, Economides AN and Gannon M: Inactivation of the dual Bmp/Wnt inhibitor Sostdcl enhances pancreatic islet function. Am J Physiol Endocrinol Metab 303 . E752-E761, 2012.
16. Itasaki N, Jones CM, Mercurio S, Rowe A, Domingos PM, Smith JC and Krumlauf R: Wise, a context-dependent activator and inhibitor of Wnt signalling. Development 130: 4295-4305, 2003.

17. Liu L, Wu S, Yang Y, Cai J, Zhu X, Wu J, Li M and Guan H: SOSTDC1 is down-regulated in non-small cell lung cancer and contributes to cancer cell proliferation. Cell Biosci 6: 24, 2016.

18. Koul R, Rathod S, Dubey A, Bashir B and Chowdhury A: Comparison of 7th and 8th editions of the UICC/AJCC TNM staging for nonsmall cell lung cancer in a non-metastatic North American cohort undergoing primary radiation treatment. Lung Cancer 123: 116-120, 2018.

19. Driver BR, Barrios R, Ge Y, Haque A, Tacha D and Cagle PT: Folate receptor $\alpha$ expression level correlates with histologic grade in lung adenocarcinoma. Arch Pathol Lab Med 140: 682-685, 2016.

20. Livak KJ and Schmittgen TD: Analysis of relative gene expression data using real-time quantitative PCR and the $2^{-\Delta \Delta C_{\mathrm{T}}}$ method. Methods 25: 402-408, 2001.

21. Wang T, Yin H, Wang J, Li Z, Wei H, Liu Z, Wu Z, Yan W, Liu T, Song D, et al: MicroRNA-106b inhibits osteoclastogenesis and osteolysis by targeting RANKL in giant cell tumor of bone. Oncotarget 6: 18980-18996, 2015.

22. Zhou W, Yin H, Wang T, Liu T, Li Z, Yan W, Song D, Chen H, Chen J, Xu W, et al: MiR-126-5p regulates osteolysis formation and stromal cell proliferation in giant cell tumor through inhibition of PTHrP. Bone 66: 267-276, 2014.

23. Laurikkala J, Kassai Y, Pakkasjärvi L, Thesleff I and Itoh N: Identification of a secreted BMP antagonist, ectodin, integrating BMP, FGF, and SHH signals from the tooth enamel knot. Dev Biol 264: 91-105, 2003.

24. Kamiya N: The role of BMPs in bone anabolism and their potential targets SOST and DKK1. Curr Mol Pharmacol 5: 153-163, 2012.

25. Okamoto M, Murai J, Yoshikawa $\mathrm{H}$ and Tsumaki N: Bone morphogenetic proteins in bone stimulate osteoclasts and osteoblasts during bone development. J Bone Miner Res 21: 1022-1033, 2006.

26. Collette NM, Yee CS, Hum NR, Murugesh DK, Christiansen BA, Xie L, Economides AN, Manilay JO, Robling AG and Loots GG: Sostdcl deficiency accelerates fracture healing by promoting the expansion of periosteal mesenchymal stem cells. Bone 88: 20-30, 2016.

27. Togo Y, Takahashi K, Saito K, Kiso H, Tsukamoto H, Huang B, Yanagita M, Sugai M, Harada H, Komori T, et al: Antagonistic functions of USAG-1 and RUNX2 during tooth development. PLoS One 11: e0161067, 2016.

28. Fujita K, Roforth MM, Demaray S, McGregor U, Kirmani S, McCready LK, Peterson JM, Drake MT, Monroe DG and Khosla S: Effects of estrogen on bone mRNA levels of sclerostin and other genes relevant to bone metabolism in postmenopausal women. J Clin Endocrinol Metab 99: E81-E88, 2014.

29. Prochazkova M, Häkkinen TJ, Prochazka J, Spoutil F, Jheon AH, Ahn Y, Krumlauf R, Jernvall J and Klein OD: FGF signaling refines Wnt gradients to regulate the patterning of taste papillae. Development 144: 2212-2221, 2017.

30. Lee JW, Wang P, Kattah MG, Youssef S, Steinman L, DeFea K and Straus DS: Differential regulation of chemokines by IL-17 in colonic epithelial cells. J Immunol 181: 6536-6545, 2008.

31. Kanda N, Hau CS, Tada Y, Tatsuta A, Sato S and Watanabe S: Visfatin enhances CXCL8, CXCL10, and CCL20 production in human keratinocytes. Endocrinology 152: 3155-3164, 2011.

32. Hardaway AL, Herroon MK, Rajagurubandara E and Podgorski I Marrow adipocyte-derived CXCL1 and CXCL2 contribute to osteolysis in metastatic prostate cancer. Clin Exp Metastasis 32: 353-368, 2015.

33. Liu P, Lee S, Knoll J, Rauch A, Ostermay S, Luther J, Malkusch N, Lerner UH, Zaiss MM, Neven M, et al: Loss of menin in osteoblast lineage affects osteocyte-osteoclast crosstalk causing osteoporosis. Cell Death Differ 24: 672-682, 2017.

This work is licensed under a Creative Commons Attribution-NonCommercial-NoDerivatives 4.0 International (CC BY-NC-ND 4.0) License. 